\title{
Relationship between Land Use Mix and Walking Choice in High-Density Cities: A Review of Walking in Seoul, South Korea
}

\author{
Eun Yeong Seong ${ }^{(D)}$, Nam Hwi Lee and Chang Gyu Choi * \\ Department of Urban and Regional Development, Hanyang University, Seoul 04763, Korea; \\ bocksil@nate.com (E.Y.S.); nabi_lee@naver.com (N.H.L.) \\ * Correspondence: cgchoi@hanyang.ac.kr
}

check for

updates

Citation: Seong, E.Y.; Lee, N.H.; Choi, C.G. Relationship between Land Use Mix and Walking Choice in High-Density Cities: A Review of Walking in Seoul, South Korea. Sustainability 2021, 13, 810 . https://doi.org/10.3390/ su13020810

Received: 14 December 2020 Accepted: 12 January 2021 Published: 15 January 2021

Publisher's Note: MDPI stays neutral with regard to jurisdictional clai$\mathrm{ms}$ in published maps and institutional affiliations.

Copyright: (C) 2021 by the authors. Licensee MDPI, Basel, Switzerland. This article is an open access article distributed under the terms and conditions of the Creative Commons Attribution (CC BY) license (https:// creativecommons.org/licenses/by/ $4.0 /)$.

\begin{abstract}
This study confirmed the general belief of urban planners that mixed land use promotes walking in Seoul, a metropolis in East Asia, by analyzing the effect of mixed land use on the travel mode choice of housewives and unemployed people who make non-commuting trips on weekdays. Using binomial logistic regression of commuting data, it was found that the more mixed a neighborhood environment's uses are, the more the pedestrians prefer to walk rather than drive. The nonlinear relationship between the land use mix index and the choice to walk was also confirmed. Although mixed land use in neighborhoods increased the probability of residents choosing walking over using cars, when the degree of complexity increased above a certain level, the opposite effect was observed. As the density of commercial areas increased, the probability of selecting walking increased. In addition to locational characteristics, income and housing type were also major factors affecting the choice to walk; i.e., when the residents' neighborhood environment was controlled for higher income and living in an apartment rather than multi-family or single-family housing, they were more likely to choose driving over walking.
\end{abstract}

Keywords: land use mix; density; walking; non-commuting trip

\section{Introduction}

Since the mid-20th century, urban planners have believed that people walk more in mixed land use and high-density areas [1,2]. The basic concept of the compact city, where more people walk and fewer people drive in walkable environments, has been proposed by the new urbanism movement and transit-oriented development (TOD). Research conducted in North America has supported this concept, demonstrating that high density and mixed land use encourages people to walk more and for longer [3-7].

Just as various North American studies have reported that increasing residential density increases walking [8-11], higher residential density also means an increase in overall demand due to a larger number of people in a given area. Seoul is one of the most densely populated cities in East Asia. Therefore, in a dense environment such as this, an increase in commercial facilities is more useful than an increase in residential facilities. Various commercial facilities that are accessible by walking from home also increase the probability of people undertaking leisure and shopping activities by walking [8,12-14], which leads to an increase in personal walking time and the pedestrian volume on the street, in turn resulting in street vitalization.

The North American studies have focused on the relationship between mixed land use and walking choice, while those on the land use mix in Seoul have analyzed pedestrian volume. The Seoul metropolitan government researched the city's pedestrian volume at a wide range of surveyed locations, offering an appropriate research opportunity to examine the relationship between pedestrian volume and land use mix (LUM) [15]. Several studies in Seoul have also revealed that mixed land use has a positive effect on pedestrian volume [15-17]. 
Seoul is a densely populated city with an excellent public transportation system. However, despite its institutional zoning regulations, the use of buildings is often allowed to overlap between zones. This mixed land use has various outcomes. For example, commercial facilities are allowed in residential areas, which means there are amenities for shopping and eating out that are accessible on foot. Figure 1 depicts two general residential areas in Seoul: (a) a low-rise residential area and (b) a high-rise apartment area. There are many types of commercial buildings accessible by walking in these residential areas, revealing that Seoul is an effective experimental space to determine the correlation between LUM in high-density areas and walking.

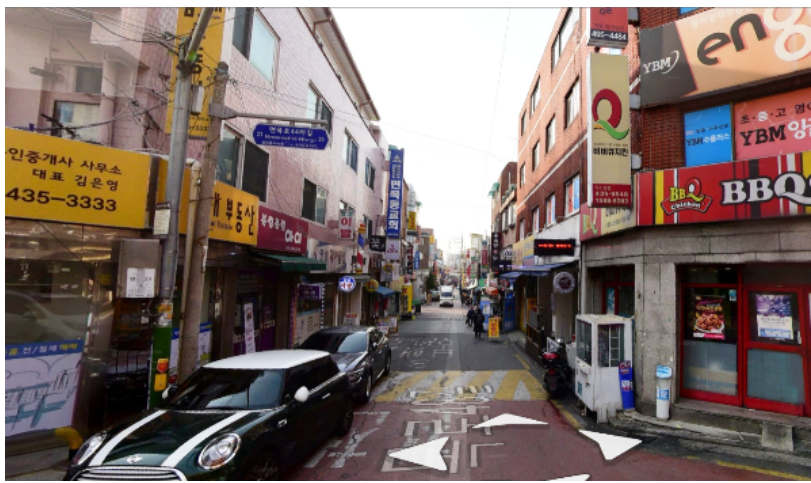

(a)

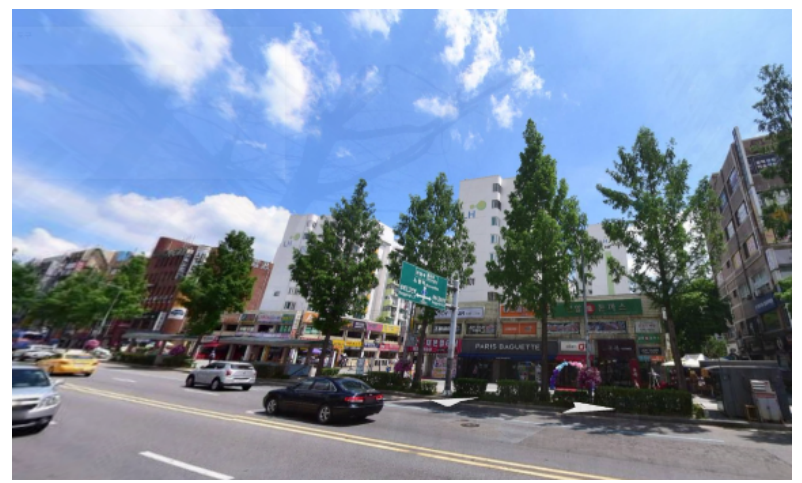

(b)

Figure 1. Typical residential areas in Seoul. (a) Retail shops in a low-rise residential area; (b) streetscape of a high-rise apartment area.

The LUM index established by Cervero and Kockelman [18] has been the most representative index used to measure land use diversity in built environment studies, including those in the fields of urban planning and design, transportation planning, and health [17]. Although some research has found that a greater land use mix results in higher rates of walking [3-6,19], other studies have found no correlation between LUM and walking distance or activities [20-23], and some others have presented a negative correlation between them $[15,16,24,25]$. This negative correlation has been mainly reported in specific areas, such as commercial districts or the city of Seoul. According to Im and Choi [15], there are nonlinear relationships between LUM and pedestrian volume in big cities such as Seoul; therefore, LUM and LUM-squared should be used together to improve this volume.

This study analyzes whether mixed land use has a positive effect on choosing to walk for transport in high-density, mixed-use, and compact cities such as Seoul. The study applies two indicators used by Im and Choi [15] and examines LUM all over Seoul, rather than just in its commercial districts. Most of the related studies on Seoul have focused on pedestrian volume; however, the present study focuses on pedestrians' choice to walk, examining the probability of residents opting to travel by car or walking to confirm the effects of neighborhood environments on their transport mode choice. Housewives and the unemployed, including students, were selected to investigate their transport mode choices on weekdays in residential areas. Based on the findings in the existing research, it was estimated that mixed land use would have a positive association with choosing to walk.

\section{Literature Review}

Various urban planning policies and studies have examined how to reduce reliance on cars and increase travel by walking. They have found that high density and a diverse neighborhood environment are the main factors that affect residents' walking activities. A monotonous, low-density residential environment such as that found in North American suburbs has been criticized for increasing dependence on automobiles. In such an environment, an increase in residential density means an increase in traffic demand. Some 
empirical studies have reported that people walk more in high-density residential areas [10,11]. According to Inoue et al. [10], built environments that incorporate aspects such as high-density housing, accessible amenities, walkability, and streetscapes promote pedestrian activities. Ewing et al. [11] compared commuting and non-commuting trips in six communities of Palm Beach County, Florida, finding that travel time per person in cars is longer in suburban sprawls than traditional cities and that mixed land use reduces vehicle travel.

On the other hand, in Seoul, a megacity in East Asia, residential density is very high, so an excessive increase in residential density may limit pedestrian access to non-residential facilities, resulting in reduced walking $[23,26]$. Increased walking in a dense residential environment is more related to the amount of commercial facilities than homes; the higher the density of commercial facilities near the residential area, the more pedestrian activity increases $[19,23,25]$. This is true for Seoul, as well. Lee and Goo [25] reported that while residential and workplace density did not affect pedestrian activity in Seoul, the number of pedestrians increased as commercial density increased. Sung et al. [19] found that the higher the non-residential-use floorage, the higher the pedestrian activity in Seoul. Lee and Choi [23] reported that more Seoul residents participate in leisure activities near their homes when commercial density is higher.

The discussion on the impact of diversity on walking behavior is more extensive. Numerous empirical studies have shown that mixed land use encourages people to walk more and longer and has a positive effect on pedestrian volume [4-8,18,27]. The more people choose to walk, the greater the pedestrian volume and vitality on streets; thus, the key to activating the streets is encouraging people to choose walking as a means of transport. Research that specifically focuses on the relationship between the neighborhood environment and walking activities can be classified into the categories of walking choice, walking time, and pedestrian volume.

Cervero and Kockelman [18] analyzed the effects of the built environment, such as density, diversity, and design, on travel demand in San Francisco Bay, USA. The study findings suggested that environment density affects choice of travel mode to work, while design factors are more influential on non-commuting trips, demonstrating that factors affecting transport mode choice vary according to the trip purpose. Meanwhile, Rajamani et al. [27] observed that mixed land use and higher residential density make people more likely to walk for leisure, shopping, and eating out rather than for work. Zhang [7] compared transport mode choices in Boston and Hong Kong, two cities with quite different environments. The results showed that land use balance did not affect commuting mode but did affect transport choices for non-commuting trips, including public transportation, walking, and cycling. Coogan et al. [5] further reported that if residential and commercial areas are in close proximity, more people choose to walk. After analyzing the Seattle area, Frank and Pivo [6] claimed that there is a strong correlation between mixed-use neighborhoods and opting to walk to work, in which people choose to walk more frequently as LUM increases. Finally, Handy and Clifton [12] focused on the factors affecting the choice to walk as an alternative to driving and found that residents in areas where commercial facilities were within walking distance preferred to walk. These studies have mainly analyzed residential areas in North America and have shown that the availability of commercial facilities in land used exclusively for residential purposes increases people's likelihood of walking. In other words, people more often choose to walk rather than use a car for shopping or eating out if there are various facilities near residential areas.

Mixed-use neighborhoods also increase walking time [28-31]. For example, Handy [28] compared traditional neighborhoods with auto-oriented suburbs and observed that residents walked or cycled 2-4 times a week more in traditional neighborhoods than suburban residential areas. Meanwhile, Duncan et al. [30] found that area-corrected LUM measures had significant positive associations with the frequency of walking for transport. Sung et al. [31] showed that neighborhoods with a higher LUM within a 500-m radius from respondents' residences had a significant positive association with walking time; 
however, no positive association was found between development density by land use and walking time. Cho and Lee [29] found that subjectively measured LUM variables are more significant for walking activities than objectively measured neighborhood environments.

While studies focusing on North America have focused on the relationship between mixed land use and choosing to walk for transport, those investigating the Seoul context have focused on pedestrian volumes [15-17,24,25]. LUM variables have a positive association with walking activity [16]: The average daily number of pedestrians increases in mixed land with residential, commercial, and business uses [25], and the average number of pedestrians on weekdays increases as LUM increases [17].

Studies targeting Seoul have revealed interesting findings. Pedestrian volumes had significant associations with mixed land use; however, there was no positive association or correlation between them in studies involving land use classification or specific districts $[15,21,24,25]$. According to Yun and Choi [24], mixed-use ground floors in commercial areas had a negative association with walking activity. Further, Lee and Koo [25] stated that mixed land use is positively associated with pedestrian volume but has no significant effect on main roads during morning rush hours, while walking volumes decrease in side streets during evening rush hours. Im and Choi [15], meanwhile, built an analytic model in Seoul. According to this model, mixed land use has a positive effect on pedestrian volume, although an opposite result was observed in central commercial business districts. Lee et al. [21] analyzed commercial districts and found no positive association between pedestrian volumes and land with mixed residential, commercial, and business uses. Nevertheless, studies that have reported no positive association or correlation between pedestrian volumes and the built environment have analyzed specific districts, such as commercial areas. It is, thus, necessary to expand the spatial scope of the LUM-related literature to include residential areas.

In a dense city such as Seoul, density and diversity will have different effects on pedestrian activities and should be considered separately. From previous studies, it can be estimated that diversity has more of an impact than density. Thus, it is very important to analyze the additional effects of LUM while controlling for density.

\section{Method}

\subsection{Variables and Data}

This study's spatial scope was the metropolis of Seoul. The city has a high population density and mixed land use, with a population of 9,720,846 and an area of about $605 \mathrm{~km}^{2}$ [32]. To analyze walking as a choice for transportation within Seoul, individual and household data were taken from the 2016 Household Travel Diary Survey [33]. This survey's data include the number of household members, types of housing, income levels, vehicles that households own, and demographic and traffic data of individuals belonging to the specific households. The study subjects were limited to housewives and unemployed persons (including students), who usually have available leisure time on weekdays. Data from weekend leisure trips were omitted since such trips often incorporate long-distance movement and have specific destinations [34]. The subjects' weekday traffic data were extracted from the survey based on their departure point for shopping, eating out, and leisure (including leisure, exercise, and tourism).

The dependent variable was the mode of transportation chosen for travel. The passengers' first choice of transportation mode was classified as either walking or driving, and the probabilities of choosing driving over walking were analyzed. The independent variables were the subjects' individual characteristics, household characteristics, location characteristics, density, and diversity, which have all been shown to affect non-work trips in previous studies.

Individual characteristics included gender, occupation, whether the person had a driver's license, and the purpose of travel. In comparison to commuter trips, noncommuting trips are made for various activities, and therefore, they required controls [35]. 
Household characteristics included the number of household members, whether the household had vehicles, whether it included preschool children, the type of house, and the average monthly household income. Housing types were classified into apartments, multifamily housing, single-family housing, and others. In Korea, there are legal distinctions between single-family housing, row housing, and detached housing; however, as they share similar physical features, they were classified together in this study. Urban formation is related to the type of housing locality; apartment buildings are likely to be in a large block formed by an urban development project, and single-family housing is likely to be found in residential areas where small lots are densely located. A household's income is a major factor in influencing the choice of transportation mode; in general, higher-income households are more likely to drive [27] and have better chances of accessing key facilities. The impacts of density and mixed land use on transportation modes were analyzed while individual and household characteristics were controlled for.

The locational characteristic variables included public transport accessibility and regional characteristics. Public transport accessibility means the walking time required from a residence to the nearest bus stop or subway station. As for the subjects' starting points, dummy variables were constructed by dividing Seoul into five regions: the central business district (CBD), southeast, northeast, southwest, and northwest. Seoul is divided into north and south by the Han River. In the center of the north (Gangbuk) is the CBD, which is home to Seoul's traditional commercial and business activity. In the south (Gangnam), the southeastern region includes the Gangnam Business District (GBD), where the commercial activities are lively and high-end housing complexes are built around large-scale apartment buildings. These regional divisions were used as variables to control for regional characteristics.

The density represented the sum of the uses of the surrounding buildings within $500 \mathrm{~m}$ of a residence. Generally, walking is affected by the surrounding built environment within a 10- to 20-min walking distance from a residence [36]; hence, the range was set at $500 \mathrm{~m}$. For those residential and commercial buildings within the 500 -m radius range, gross floor areas were calculated based on the 2015 Seoul Metropolitan Government Taxation Ledger. Office floor area was not considered for the analysis as it is highly correlated with commercial use.

The diversity variables are LUM4 and LUM4-squared. LUM4 is an index for identifying mixed land use characteristics, constructed by the area ratio of the following four uses: residential, commercial, offices, and others. The areas were also extracted from the 2015 Seoul Metropolitan Government Taxation Ledger [37]. The LUM4 index includes values from 0 to 1 ; the closer this value is to 1 , the higher the mixed land use that has been achieved [3] (see Table 1). 
Table 1. Definition of variables.

\begin{tabular}{|c|c|c|}
\hline Variable & Description & Data Sources \\
\hline Travel mode & Walking (ref.); driving & Household Travel Diary Survey (2016) \\
\hline \multicolumn{3}{|c|}{ Personal characteristics } \\
\hline $\begin{array}{c}\text { Gender } \\
\text { Driver's license } \\
\text { Job } \\
\text { Travel purpose }\end{array}$ & $\begin{array}{c}\text { Male (ref.); female } \\
\text { No (ref.); yes } \\
\text { Unemployed/student (ref.); housewife } \\
\text { Dining out (ref.); shopping; leisure }\end{array}$ & Household Travel Diary Survey (2016) \\
\hline \multicolumn{3}{|c|}{ Household characteristics } \\
\hline $\begin{array}{l}\text { No. of family members } \\
\text { Car ownership } \\
\text { Preschool-aged children } \\
\text { House type } \\
\text { Monthly household income }\end{array}$ & $\begin{array}{c}\text { Person } \\
\text { Yes (ref.); no } \\
\text { Yes (ref.); no } \\
\text { Apartment (ref.); multi-family housing; } \\
\text { single-family housing; other } \\
\text { Over KRW } 5 \text { million (ref.); between KRW } \\
5 \text { million and } 3 \text { million; under KRW } 3 \text { million }\end{array}$ & Household Travel Diary Survey (2016) \\
\hline \multicolumn{3}{|c|}{ Locational characteristics } \\
\hline $\begin{array}{c}\text { Proximity to bus stop } \\
\text { Proximity to subway station } \\
\text { Starting area }\end{array}$ & $\begin{array}{l}\text { Walking time to the nearest bus stop (minutes) } \\
\text { Walking time to the nearest subway station } \\
\text { (minutes) } \\
\text { Southeastern area (ref.); CBD area; northeast } \\
\text { area; southwestern area; northwest area }\end{array}$ & Household Travel Diary Survey (2016) \\
\hline \multicolumn{3}{|c|}{ Density } \\
\hline $\begin{array}{l}\text { Residential density } \\
\text { Commercial density }\end{array}$ & $\begin{array}{l}\text { Total residential floor area within a 500-m } \\
\text { radius }\left(\mathrm{km}^{2}\right) \\
\text { Total commercial floor area within a 500-m } \\
\text { radius }\left(\mathrm{km}^{2}\right)\end{array}$ & Seoul Metropolitan Tax Ledger (2015) \\
\hline \multicolumn{3}{|l|}{ Diversity } \\
\hline LUM4 & $\begin{array}{l}\text { Entropy index of residential, commercial, } \\
\text { office, and other use }\end{array}$ & Seoul Metropolitan Tax Ledger (2015) \\
\hline
\end{tabular}

Notes: KRW $1022 \fallingdotseq$ USD 1 (December 2016). CBD—central business district.

\subsection{Binomial Logistic Regression Model}

A binomial logistic regression model was applied to analyze the characteristics of individuals, households, location, density, and diversity that influenced the travel mode choice for non-commuting trips, including the probability of choosing driving over walking. The binomial logistic regression model is as follows:

$$
\begin{aligned}
& \log \left[\frac{\mathrm{P}(\mathrm{y}=\mathrm{b})}{\mathrm{P}(\mathrm{y}=\mathrm{a})}\right]=\alpha+\beta_{\mathrm{a} 1} \mathrm{x}_{\mathrm{a} 1}+\beta_{\mathrm{a} 2} \mathrm{x}_{\mathrm{a} 2}+\beta_{\mathrm{a} 3} \mathrm{x}_{\mathrm{a} 3}+\beta_{\mathrm{a} 4} \mathrm{x}_{\mathrm{a} 4}+\beta_{\mathrm{b} 5} \mathrm{x}_{\mathrm{b} 5}+\beta_{\mathrm{b} 6} \mathrm{x}_{\mathrm{b} 6}+\beta_{\mathrm{b} 7} \mathrm{x}_{\mathrm{b} 7}+\beta_{\mathrm{b} 8} \mathrm{x}_{\mathrm{b} 8}+\beta_{\mathrm{b} 9} \mathrm{x}_{\mathrm{b} 9}+\beta_{\mathrm{c} 10} \mathrm{x}_{\mathrm{c} 10} \\
& +\beta_{\mathrm{c} 11} x_{\mathrm{c} 11}+\beta_{\mathrm{c} 12} x_{\mathrm{c} 12} \\
& \log \left[\frac{\mathrm{P}(\mathrm{y}=\mathrm{b})}{\mathrm{P}(\mathrm{y}=\mathrm{a})}\right]=\alpha+\beta_{\mathrm{a} 1} \mathrm{x}_{\mathrm{a} 1}+\beta_{\mathrm{a} 2} \mathrm{x}_{\mathrm{a} 2}+\beta_{\mathrm{a} 3} \mathrm{x}_{\mathrm{a} 3}+\beta_{\mathrm{a} 4} \mathrm{x}_{\mathrm{a} 4}+\beta_{\mathrm{b} 5} \mathrm{x}_{\mathrm{b} 5}+\beta_{\mathrm{b} 6} \mathrm{x}_{\mathrm{b} 6}+\beta_{\mathrm{b} 7} \mathrm{x}_{\mathrm{b} 7}+\beta_{\mathrm{b} 8} \mathrm{x}_{\mathrm{b} 8}+\beta_{\mathrm{b} 9} \mathrm{x}_{\mathrm{b} 9}+\beta_{\mathrm{c} 10} \mathrm{x}_{\mathrm{c} 10} \\
& +\beta_{\mathrm{c} 11} \mathrm{x}_{\mathrm{c} 11}+\beta_{\mathrm{c} 12} \mathrm{x}_{\mathrm{c} 12}+\beta_{\mathrm{d} 13} \mathrm{x}_{\mathrm{d} 13}+\beta_{\mathrm{d} 14} \mathrm{x}_{\mathrm{d} 14} \\
& \log \left[\frac{\mathrm{P}(\mathrm{y}=\mathrm{b})}{\mathrm{P}(\mathrm{y}=\mathrm{a})}\right]=\alpha+\beta_{\mathrm{a} 1} \mathrm{x}_{\mathrm{a} 1}+\beta_{\mathrm{a} 2} \mathrm{x}_{\mathrm{a} 2}+\beta_{\mathrm{a} 3} \mathrm{x}_{\mathrm{a} 3}+\beta_{\mathrm{a} 4} \mathrm{x}_{\mathrm{a} 4}+\beta_{\mathrm{b} 5} \mathrm{x}_{\mathrm{b} 5}+\beta_{\mathrm{b} 6} \mathrm{x}_{\mathrm{b} 6}+\beta_{\mathrm{b} 7} \mathrm{x}_{\mathrm{b} 7}+\beta_{\mathrm{b} 8} \mathrm{x}_{\mathrm{b} 8}+\beta_{\mathrm{b} 9} \mathrm{x}_{\mathrm{b} 9}+\beta_{\mathrm{c} 10} \mathrm{x}_{\mathrm{c} 10} \\
& +\beta_{\mathrm{c} 11} \mathrm{x}_{\mathrm{c} 11}+\beta_{\mathrm{c} 12} \mathrm{x}_{\mathrm{c} 12}+\beta_{\mathrm{d} 13} \mathrm{x}_{\mathrm{d} 13}+\beta_{\mathrm{d} 14} \mathrm{x}_{\mathrm{d} 14}+\beta_{\mathrm{e} 15} \mathrm{x}_{\mathrm{e} 15} \\
& \log \left[\frac{\mathrm{P}(\mathrm{y}=\mathrm{b})}{\mathrm{P}(\mathrm{y}=\mathrm{a})}\right]=\alpha+\beta_{\mathrm{a} 1} \mathrm{x}_{\mathrm{a} 1}+\beta_{\mathrm{a} 2} \mathrm{x}_{\mathrm{a} 2}+\beta_{\mathrm{a} 3} \mathrm{x}_{\mathrm{a} 3}+\beta_{\mathrm{a} 4} \mathrm{x}_{\mathrm{a} 4}+\beta_{\mathrm{b} 5} \mathrm{x}_{\mathrm{b} 5}+\beta_{\mathrm{b} 6} \mathrm{x}_{\mathrm{b} 6}+\beta_{\mathrm{b} 7} \mathrm{x}_{\mathrm{b} 7}+\beta_{\mathrm{b} 8} \mathrm{x}_{\mathrm{b} 8}+\beta_{\mathrm{b} 9} \mathrm{x}_{\mathrm{b} 9}+\beta_{\mathrm{c} 10} \mathrm{x}_{\mathrm{c} 10} \\
& +\beta_{\mathrm{c} 11} \mathrm{x}_{\mathrm{c} 11}+\beta_{\mathrm{c} 12} \mathrm{x}_{\mathrm{c} 12}+\beta_{\mathrm{d} 13} \mathrm{x}_{\mathrm{d} 13}+\beta_{\mathrm{d} 14} \mathrm{x}_{\mathrm{d} 14}+\beta_{\mathrm{e} 15} \mathrm{x}_{\mathrm{e} 15}+\beta_{\mathrm{e} 16} \mathrm{x}_{\mathrm{e} 16}
\end{aligned}
$$


where $\mathrm{a}$ and $\mathrm{b}$ represent each non-commuting mode of transportation; a represents "walking", which is used as the reference category, and b corresponds to "driving"; $\beta_{\mathrm{n}}$ is the coefficient of each explanatory variable, and $x$ is the independent variables; $x_{a n}$ stands for personal characteristics, and $\mathrm{x}_{\mathrm{bn}}, \mathrm{x}_{\mathrm{cn}}, \mathrm{x}_{\mathrm{dn}}$, and, $\mathrm{x}_{\mathrm{en}}$ are household characteristics, locational characteristics, density, and diversity, respectively; $x_{a 1}$ stands for the gender variable, and $\mathrm{x}_{\mathrm{a} 2}, \mathrm{x}_{\mathrm{a} 3}$, and $\mathrm{x}_{\mathrm{a} 4}$ are variables of driver's license, job, and travel purpose, respectively; $\mathrm{x}_{\mathrm{b} 5}$ stands for the number of family members variable, and $\mathrm{x}_{\mathrm{b} 6}, \mathrm{x}_{\mathrm{b} 7}, \mathrm{x}_{\mathrm{b} 8}$, and $\mathrm{x}_{\mathrm{b} 9}$ are variables of car ownership, preschool-aged children, housing type, and monthly household income, respectively; $\mathrm{x}_{\mathrm{c} 10}$ stands for proximity to a bus stop, and $\mathrm{x}_{\mathrm{c} 11}$ and $\mathrm{x}_{\mathrm{c} 12}$ are variables of proximity to a subway station and starting area; $x_{\mathrm{d} 13}$ stands for residential density and $\mathrm{x}_{\mathrm{d} 14}$ is commercial density variable; $\mathrm{x}_{\mathrm{e} 15}$ stands for LUM4 and $\mathrm{x}_{\mathrm{e} 16}$ is the LUM4-squared variable.

\section{Results}

\subsection{Descriptive Statistics}

It was found that $78.4 \%$ of the subjects were walking for non-commuting trips during the weekdays (see Table 2). Walking was significantly more common compared to driving $(21.6 \%)$. Furthermore, $53.0 \%$ of respondents did not have a driver's license. In terms of occupation, there were more housewives $(71.8 \%)$ than students (unemployed) $(28.2 \%)$. The main purposes of their travel were shopping $(47.1 \%)$, leisure (43.8\%), and dining out $(9.1 \%)$.

Table 2. Descriptive analysis.

\begin{tabular}{|c|c|c|c|c|c|}
\hline Variable & & Mean $/ n$ & SD/Ratio & Min. & Max. \\
\hline \multirow[b]{2}{*}{ Travel mode } & Walking & 2981 & 78.4 & & \\
\hline & Driving & 822 & 21.6 & & \\
\hline \multicolumn{6}{|c|}{ Personal characteristics } \\
\hline \multirow{2}{*}{ Gender } & Male & 697 & 18.3 & & \\
\hline & Female & 3106 & 81.7 & & \\
\hline \multirow{2}{*}{ Driver's license } & Yes & 1789 & 47.0 & & \\
\hline & No & 2014 & 53.0 & & \\
\hline \multirow{2}{*}{ Job } & Unemployed/student & 1073 & 28.2 & & \\
\hline & Housewife & 2730 & 71.8 & & \\
\hline \multirow{3}{*}{ Travel purpose } & Dining out & 347 & 9.1 & & \\
\hline & Shopping & 1797 & 47.1 & & \\
\hline & Leisure & 1664 & 43.8 & & \\
\hline \multicolumn{6}{|c|}{ Household characteristics } \\
\hline \multicolumn{2}{|c|}{ No. of family members (person) } & 2.7 & 1.1 & 1 & 8 \\
\hline \multirow{2}{*}{ Car ownership } & No & 1379 & 36.3 & & \\
\hline & Yes & 2424 & 63.7 & & \\
\hline \multirow{2}{*}{ Preschool-aged children } & No & 3353 & 88.2 & & \\
\hline & Yes & 450 & 11.8 & & \\
\hline \multirow{4}{*}{ House type } & Apartment & 1973 & 51.9 & & \\
\hline & Multi-family housing & 487 & 12.8 & & \\
\hline & Single-family housing & 1302 & 34.2 & & \\
\hline & Other & 41 & 1.1 & & \\
\hline \multirow{3}{*}{ Monthly household income } & Over KRW 5 million & 695 & 18.3 & & \\
\hline & $\begin{array}{l}\text { Between KRW } 5 \text { million and } \\
\qquad 3 \text { million }\end{array}$ & 1265 & 33.3 & & \\
\hline & Under KRW 3 million & 1843 & 48.5 & & \\
\hline
\end{tabular}


Table 2. Cont.

\begin{tabular}{|c|c|c|c|c|c|}
\hline Variable & & Mean $/ n$ & SD/Ratio & Min. & Max. \\
\hline \multicolumn{6}{|c|}{ Locational characteristics } \\
\hline \multirow{2}{*}{\multicolumn{2}{|c|}{$\begin{array}{l}\text { Proximity to bus stop (min) } \\
\text { Proximity to subway station (min) }\end{array}$}} & 5.2 & 2.6 & 1 & 19 \\
\hline & & 12.0 & 7.3 & 1 & 55 \\
\hline \multirow{5}{*}{ Starting area } & Southeastern area & 704 & 18.5 & & \\
\hline & CBD area & 282 & 7.4 & & \\
\hline & Northeast area & 617 & 16.2 & & \\
\hline & Southwestern area & 1640 & 43.1 & & \\
\hline & Northwest area & 560 & 14.7 & & \\
\hline \multicolumn{6}{|l|}{ Density } \\
\hline \multirow{2}{*}{\multicolumn{2}{|c|}{$\begin{array}{l}\text { Residential density }\left(\mathrm{km}^{2}\right) \\
\text { Commercial density }\left(\mathrm{km}^{2}\right)\end{array}$}} & 11.3 & 14.1 & 0 & 136.2 \\
\hline & & 0.6 & 0.7 & 0 & 11.2 \\
\hline \multicolumn{6}{|c|}{ Diversity } \\
\hline \multicolumn{2}{|c|}{ LUM4 } & 0.30 & 0.20 & 0.00 & 0.97 \\
\hline \multicolumn{2}{|c|}{ LUM4-squared } & 0.13 & 0.16 & 0.00 & 0.94 \\
\hline
\end{tabular}

In terms of household demographics, the average number of household members was 2.7 people. Additionally, $63.7 \%$ of households owned vehicles, and $11.8 \%$ included preschool children. Apartments (51.9\%) were the most common housing type, followed by single-family housing (34.2\%). Under KRW 3 million was the most common average monthly income, accounting for $48.5 \%$ of the sample group. The average walking time to the nearest bus stop from the respondents' residences was $5.2 \mathrm{~min}$, and to the subway station was $12.0 \mathrm{~min}$. The standard deviation was smaller than the mean value, indicating good overall accessibility of public transportation.

The average gross housing area within the $500-\mathrm{m}$ residential buffer was $11.3 \mathrm{~km}^{2}$, and the average gross commercial area was $0.6 \mathrm{~km}^{2}$. Both residential and commercial uses showed a larger standard deviation than the mean value, meaning that the departure points included land use in various hierarchies. The average LUM4 value was 0.30. As for the starting regions to which the residences belonged, the highest frequency was found in the southwest $(43.1 \%)$, followed by southeast $(18.5 \%)$, northeast $(16.2 \%)$, northwest $(14.7 \%)$, and the city center $(7.4 \%)$.

Independent variables were validated for any differences between the groups that chose different transportation modes. A $t$-test was performed for the continuous variables, while a chi-square test was used for the nominal variables. The observed results revealed significant differences for all variables between each group (see Table 3).

Table 3. Descriptive analysis by travel mode.

\begin{tabular}{|c|c|c|c|c|c|c|c|}
\hline & \multirow[t]{2}{*}{ Variable } & & \multicolumn{2}{|c|}{ Walking } & \multicolumn{2}{|c|}{ Driving } & \multirow[t]{2}{*}{$\begin{array}{c}t \text {-Value } \\
\text { /chi-square }\end{array}$} \\
\hline & & & Mean $/ n$ & SD/Ratio & Mean $/ n$ & SD/Ratio & \\
\hline \multirow{5}{*}{$\begin{array}{l}\text { Personal } \\
\text { characteris- } \\
\text { tics }\end{array}$} & \multirow[t]{2}{*}{ Gender } & Male & 601 & 20.2 & 96 & 11.7 & $\begin{array}{l}X^{2}=30.970 \\
p=0.000^{* * *}\end{array}$ \\
\hline & & Female & 2380 & 79.8 & 726 & 88.3 & \\
\hline & \multirow[t]{2}{*}{ Driver's license } & Yes & 1119 & 37.5 & 670 & 81.5 & $\begin{array}{l}X^{2}=500.056 \\
p=0.000^{* * *}\end{array}$ \\
\hline & & No & 1862 & 62.5 & 152 & 18.5 & \\
\hline & Job & $\begin{array}{l}\text { Unemployed/ } \\
\text { student }\end{array}$ & 907 & 30.4 & 166 & 20.2 & $\begin{array}{l}\mathrm{X}^{2}=33.302 \\
p=0.000^{* * *}\end{array}$ \\
\hline
\end{tabular}


Table 3. Cont

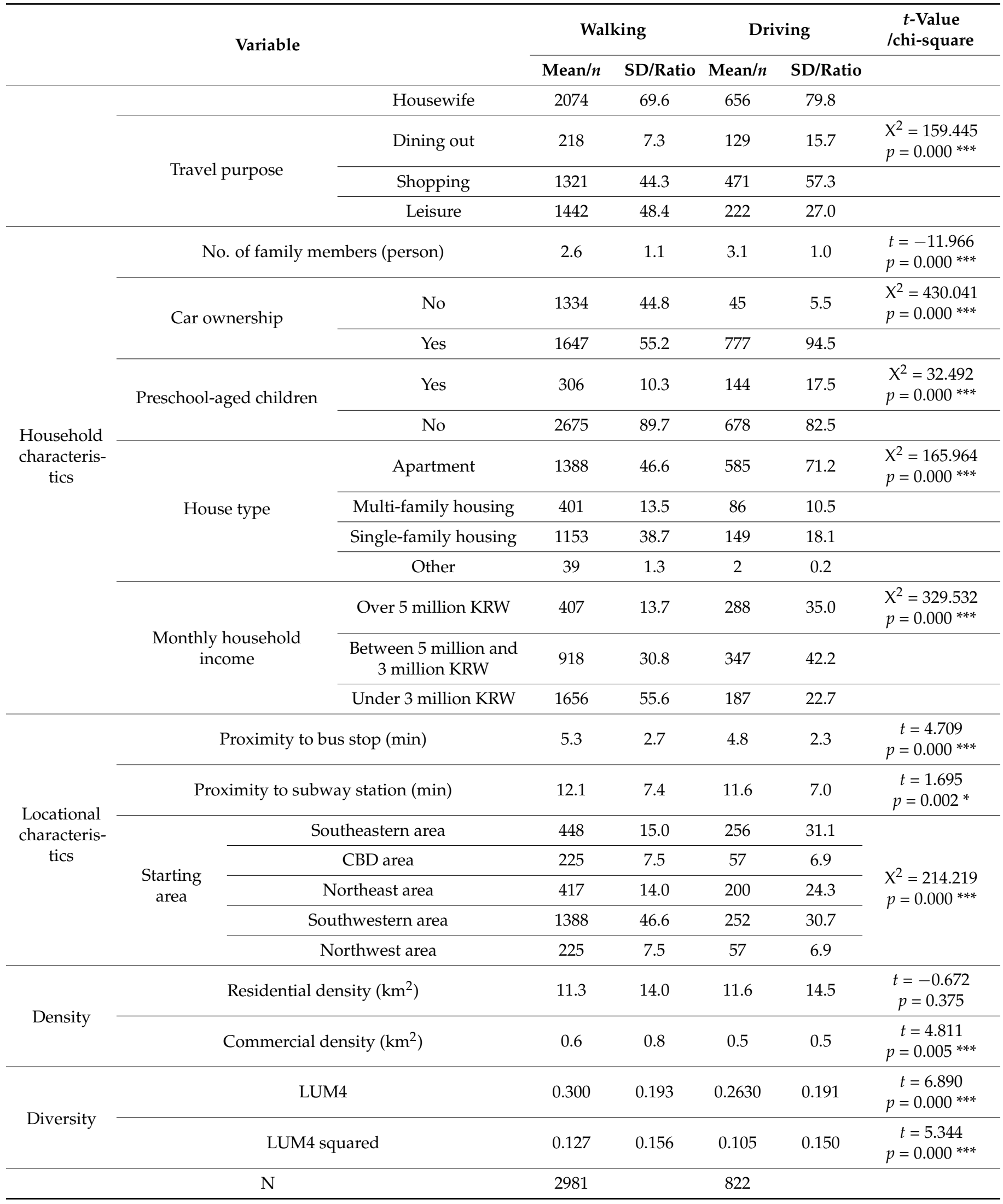


For the respondents who chose to drive rather than walk, there was a relatively higher proportion of women (88.3\%). Of all respondents who chose to drive, $81.5 \%$ had a driver's license, and the proportion of housewives was high (79.8\%). Leisure (48.4\%) and shopping $(44.3 \%)$ were the main purposes of the trip for those who chose to walk, while the majority of those who chose to drive did so for shopping (57.3\%).

In terms of household characteristics, the average number of household members who chose driving was 3.1 versus 2.6 who chose walking. Of the households who chose driving, $94.5 \%$ owned a car, $82.5 \%$ did not have preschool-aged children, $71.2 \%$ lived in apartments, and $42.2 \%$ had a monthly income between KRW 3 and 5 million. Of the households who chose walking, 46.6\% lived in apartments, 38.7\% lived in single-family housing, and 55.6\% had a monthly income of less than KRW three million. Overall, the households who chose to walk had a higher number of household members, lived in detached houses, and had lower incomes compared to those who chose driving.

Respondents who chose to walk did so for a higher percentage of leisure purposes $(48.4 \%)$ compared with those who chose driving. The proportion of low-income households $(55.6 \%)$, that is, those earning less than KRW three million a month, was high among those who chose to walk. Presumably, people choose to walk for leisure, exercise, and tourism; however, those from low-income households also likely choose to walk because it costs less than driving.

Those who chose driving more frequently traveled for shopping (57.3\%) and eating out $(15.7 \%)$. In terms of housing type, those living in apartments $(71.2 \%)$ drove significantly more than those living in other housing types. Driving was more common among households with an income level of more than KRW five million per month (35.0\%) than walking $(13.7 \%)$. The southeast was the most frequent starting region for driving at $31.1 \%$. Therefore, in summary, respondents who choose to drive can be assumed to have higher household incomes and live in apartments that represent middle-class housing types, located in the southeastern region of Seoul. This demonstrates the very different economic characteristics of households between those who choose walking and those who choose to drive.

There was a significant difference in the time taken from respondents' residences to bus stops and subway stations; however, between those who chose walking and those who chose driving, even though they had better access to public transportation, the time difference was less than one minute. Seoul has a highly developed public transportation network, meaning that few areas have limited public transportation access.

The commercial density corresponding to respondents who chose to walk was higher on average than for those who chose to drive. The same results were found for LUM; respondents who chose to walk showed high LUM. When residential areas had high densities of commercial buildings, the respondents tended to choose to walk, and the mixed land use index was the highest in the residential area where the residents chose to walk. It is presumed that the probability of choosing walking increases when retail shops are within walking distance [4].

Based on the descriptive statistics, differences in households' socio-economic characteristics and individual characteristics were analyzed in terms of which respondents chose walking or driving. It was assumed that pedestrians living in areas with diverse land uses and high density would choose to walk often. To investigate the impact of high density and mixed land use on transportation mode choices, the individual and socio-economic characteristics of households were controlled for.

\subsection{Factors Affecting Travel Mode Choice for Non-Commuting Trips}

This section aims to analyze the patterns of transportation mode choice for noncommuting trips by using the binomial logistic regression model with control variables. To analyze the effect of diversity on choosing to walk in dense cities, density and diversity were added in order and analyzed. Model 1 was built with the characteristics of personal, household, and location. Model 2 added density. Im and Choi [15] argued for a nonlinear 
relationship between walking volume and LUM in large cities such as Seoul. In the present study, the LUM4 and LUM4-squared variables were applied step-by-step to analyze this nonlinearity. Model 3 was built only for LUM4, while Model 4 was constructed for LUM4squared. The maximum likelihood method was used for the estimation, and the results are shown in Table 4.

The Nagelkerke R2 values, a measure of the models' explanatory power, were 0.388 to 0.397, indicating that the models explained approximately $38.8-39.7 \%$ of the response variable. In addition, in Hosmer and Lemeshow's test for measuring the concordance of the observed and predicted values of the dependent variable, the null hypothesis was not rejected with chi-squared values ( $p$-values) of 9.575 (0.296), $9.636(0.292), 10.609(0.225)$, and $3.406(0.906)$, thus revealing that there was no difference between the observed and the predicted values.

The information in the classification table can be used to evaluate the utility of binary linear regression models by comparing the overall percentage correct with the proportion by chance accuracy criteria (PCC). This is calculated by squaring and summing the proportion of cases for each group [38]. The classification accuracy should be at least $25 \%$ greater than that achieved by chance. The PCC calculated from the cases for each group is 0.66 and the hit ratio should, then, be at least $82.6 \%$. The hit ratio for Model 2 and Model 4 is $82.7 \%$ and $83.2 \%$ respectively. This means that the classification accuracy is significantly better than that achieved by chance. The hit rates of Model 1 and Model 3 are $82.4 \%$ and $82.5 \%$, respectively, which are slightly lower than the appropriate criteria. The interpretation of the results in this study was based on the best-fit Model 4.

Commercial facility density had a significant negative influence on the choice to drive (Model 2-4). It was found that when a commercial area's density was high, residents were more likely to walk than drive for non-commuting trips, and as the density of commercial facilities increased, respondents chose to walk rather than drive. This result is consistent with that of a study conducted for suburban areas in North America [8-11].

A nonlinear relationship was confirmed as (-) for LUM4 and (+) for LUM4-squared (Model 4). LUM4 alone did not affect the choice to drive; however, it had significant meaning when it was considered simultaneously with LUM4-squared. While LUM4 had a negative effect on the choice to drive for non-commuting trips, LUM4-squared had a positive impact. This allows us to assume the grounds to claim that there is no statistical significance between the LUM4 index factors and walking $[19,21,22,30]$. In the case of North American cities, based on exclusive land use, a linear relationship can be estimated between LUM and walking choice; however, in the case of high-density and mixed-use cities, a nonlinear relationship should be considered when measuring the effects of mixeduse land. In order to reduce the use of cars and increase non-powered transportation modes, mixed land use needs to be promoted rather than raising an area's density.

All the personal characteristic variables influenced the choice to drive. Women were more likely to choose driving when eating out than when going shopping or enjoying leisure activities, and this was even more common if they possessed a driver's license. The household characteristics that had a major influence on walking choice were income and housing type. Residents in mixed-use neighborhoods with similar conditions chose to drive rather than walk for non-commuting trips when their income was higher and they lived in apartments rather than single-family or multi-family buildings. Apartments represent middle-class housing and, therefore, are also indicative of residents' income and economic status. Households that owned vehicles, included preschool children, or earned a high income of more than KRW five million a month more frequently chose to drive than to walk. 
Table 4. Binomial logit model for predicting travel mode choice for non-work trips from home base (ref. = walking).

\begin{tabular}{|c|c|c|c|c|c|c|c|c|c|c|c|c|c|c|}
\hline & & & \multicolumn{3}{|c|}{ MODEL1 } & \multicolumn{3}{|c|}{ MODEL2 } & \multicolumn{3}{|c|}{ MODEL3 } & \multicolumn{3}{|c|}{ MODEL4 } \\
\hline & & & B & & $\operatorname{Exp}(B)$ & B & & $\operatorname{Exp}(B)$ & B & & $\operatorname{Exp}(B)$ & B & & $\operatorname{Exp}(B)$ \\
\hline & \multicolumn{2}{|c|}{ Constant } & 0.532 & & 1.702 & 0.756 & * & 2.130 & 0.819 & $* *$ & 2.269 & 1.341 & $* * *$ & 3.821 \\
\hline \multirow{4}{*}{$\begin{array}{c}\text { Personal } \\
\text { characteristics }\end{array}$} & \multicolumn{2}{|c|}{ Driver's license $($ no $=0$, yes $=1$ ) } & 1.453 & $* * *$ & 4.275 & 1.439 & $* * *$ & 4.216 & 1.437 & $* * *$ & 4.208 & 1.432 & $* * *$ & 4.187 \\
\hline & \multicolumn{2}{|c|}{ Job (unemployed $/$ student $=0$, housewife $=1$ ) } & -0.464 & $* * *$ & 0.629 & -0.467 & $* * *$ & 0.627 & -0.468 & $* * *$ & 0.626 & -0.483 & $* * *$ & 0.617 \\
\hline & \multirow{2}{*}{$\begin{array}{l}\text { Purpose of travel } \\
\text { (ref = eating out) }\end{array}$} & Shopping & -0.512 & $* * *$ & 0.599 & -0.515 & $* * *$ & 0.598 & -0.513 & $* * *$ & 0.599 & -0.495 & $* * *$ & 0.610 \\
\hline & & Leisure & -1.200 & $* * *$ & 0.301 & -1.209 & $* * *$ & 0.299 & -1.206 & $* * *$ & 0.299 & -1.220 & $* * *$ & 0.295 \\
\hline \multirow{8}{*}{$\begin{array}{l}\text { Household } \\
\text { characteristics }\end{array}$} & \multicolumn{2}{|c|}{ No. of family members } & -0.100 & * & 0.905 & -0.104 & * & 0.901 & -0.106 & * & 0.900 & -0.104 & * & 0.902 \\
\hline & \multicolumn{2}{|c|}{ Car ownership (yes $=0$, no $=1$ ) } & -1.598 & $* * *$ & 0.202 & -1.593 & $* * *$ & 0.203 & -1.592 & $* * *$ & 0.204 & -1.598 & $* * *$ & 0.202 \\
\hline & \multicolumn{2}{|c|}{ Preschool-aged children $($ yes $=0$, no $=1$ ) } & -0.229 & $*$ & 0.795 & -0.270 & * & 0.763 & -0.267 & * & 0.765 & -0.267 & * & 0.765 \\
\hline & \multirow{3}{*}{$\begin{array}{c}\text { House type } \\
\text { (ref. = Apartment) }\end{array}$} & Multi-family housing & -0.359 & $* *$ & 0.698 & -0.329 & $* *$ & 0.720 & -0.316 & $* *$ & 0.729 & -0.305 & * & 0.737 \\
\hline & & Single-family housing & -0.722 & $* * *$ & 0.486 & -0.663 & $* * *$ & 0.515 & -0.651 & $* * *$ & 0.521 & -0.630 & $* * *$ & 0.533 \\
\hline & & Other & -1.866 & $* *$ & 0.155 & -1.775 & $* *$ & 0.170 & -1.759 & $* *$ & 0.172 & -1.753 & $* *$ & 0.173 \\
\hline & \multirow{2}{*}{$\begin{array}{c}\text { Monthly household } \\
\text { income } \\
\text { (ref. = over KRW } 5 \text { million) }\end{array}$} & Under KRW 3 million & -0.602 & $* * *$ & 0.548 & -0.606 & $* * *$ & 0.545 & -0.607 & $* * *$ & 0.545 & -0.590 & $* * *$ & 0.554 \\
\hline & & $\begin{array}{c}\text { Between KRW } \\
5 \text { million and } 3 \text { million }\end{array}$ & -0.327 & $* * *$ & 0.721 & -0.315 & $* *$ & 0.730 & -0.314 & $* *$ & 0.730 & -0.318 & $* * *$ & 0.728 \\
\hline \multirow{6}{*}{$\begin{array}{l}\text { Locational } \\
\text { characteristics }\end{array}$} & \multicolumn{2}{|c|}{ Proximity to bus stop } & -0.069 & $* * *$ & 0.934 & -0.061 & $* * *$ & 0.941 & -0.061 & $* * * *$ & 0.941 & -0.064 & $* * *$ & 0.938 \\
\hline & \multicolumn{2}{|c|}{ Proximity to subway station } & 0.008 & & 1.008 & 0.005 & * & 1.005 & 0.004 & & 1.004 & 0.001 & & 1.001 \\
\hline & \multirow{4}{*}{$\begin{array}{c}\text { Starting area } \\
\text { (ref. }=\text { Southeastern area) }\end{array}$} & CBD area & -0.437 & $* *$ & 0.646 & -0.516 & $* *$ & 0.597 & -0.504 & $* *$ & 0.604 & -0.531 & $* * *$ & 0.588 \\
\hline & & Northeastern area & 0.049 & & 1.051 & -0.016 & & 0.984 & -0.012 & & 0.988 & -0.004 & & 0.996 \\
\hline & & Southwestern area & -0.986 & $* * *$ & 0.373 & -0.991 & $* * *$ & 0.371 & -0.980 & $* * * *$ & 0.375 & -0.935 & $* * *$ & 0.392 \\
\hline & & Northwestern area & -1.427 & $* * *$ & 0.240 & -1.516 & $* * *$ & 0.220 & -1.511 & $* * *$ & 0.221 & -1.495 & $* * *$ & 0.224 \\
\hline
\end{tabular}


Table 4. Cont.

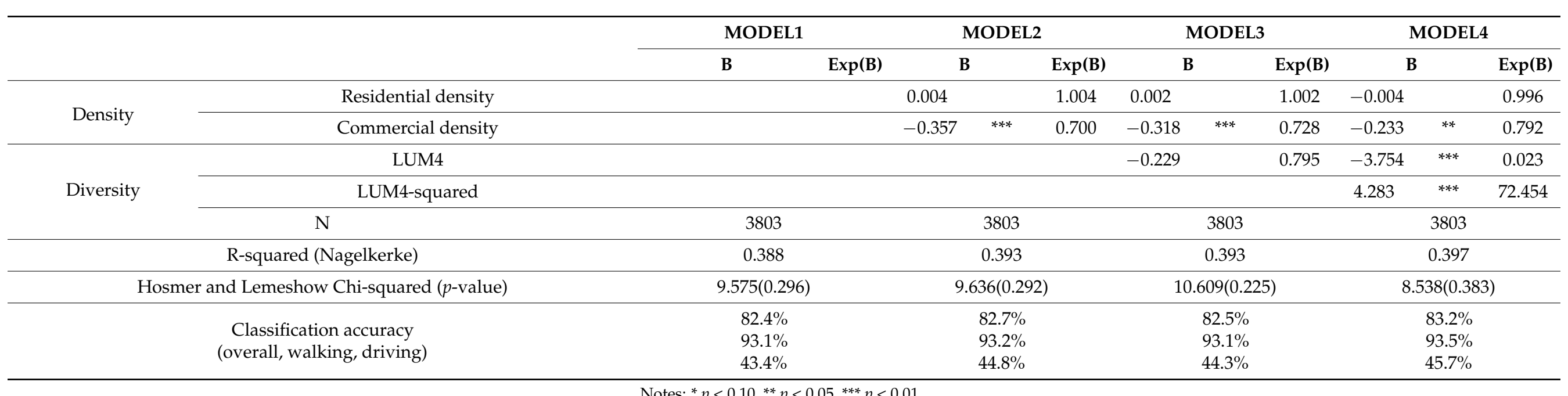

Notes: ${ }^{*} p<0.10,{ }^{* *} p<0.05,{ }^{* * *} p<0.01$. 
Locational characteristics had some influence on choosing to drive. Subway station accessibility did not have a significant effect, while respondents were more likely to choose to walk if the bus stop was farther away. These findings contradict the general idea. As mentioned in Section 4.1, Seoul has an efficient public transportation system, so citizens have access to high-quality services in most areas. However, some low-income residents with poor access to bus stops have no choice but to walk even if the bus stop is far away.

Driving was a more frequent travel mode choice in the southeast region of Seoul compared with the city's other regions, except for the northeastern area. This is unsurprising since Seoul's high-end residential areas are located in the southeast of the city, and it was more likely that residents would choose to drive rather than walk for non-commuting trips in the southeast if their households had higher incomes and they lived in apartments, which are a representative form of housing for the Korean middle class.

\section{Conclusions}

In general, various attempts have been made to reduce dependence on cars and promote walking. The density and diversity of neighborhood environments are characteristics used for creating more walkable environment by urban planners. This study focused on the effect of diversity rather than density in a dense neighborhood environment. The higher the density of commercial facilities, the more likely it was that residents would choose walking over driving. The belief that mixed land uses promote walking was confirmed by the results of the analysis of the transportation mode choices of non-commuters living in Seoul. The more mixed a neighborhood's land use, the more likely the surveyed residents were to choose to walk rather than drive. The LUM4 index factors alone did not affect the choice to walk; however, they had significant meaning in the nonlinear relationship when the LUM4-squared variable that was simultaneously considered. Finally, it was found that non-commuters who departed from home on weekdays in mixed-use neighborhoods preferred to walk rather than drive.

Although the accuracy of the present study's analysis was improved by collecting neighborhood information via residents' addresses, it has some limitations. This study used data from a survey that was mainly meant to collect information on the traveler's origin and destination, and the choice of transportation mode was a supplementary question. Although it is the largest survey available regarding information on transportation mode choice, it is limited by low precision. If a separate professional questionnaire is conducted, the accuracy of the study may increase.

Author Contributions: All authors have contributed to the idea of the paper. E.Y.S. developed research design, analyzed the data and wrote the manuscript. N.H.L. provided the idea of the paper and constructed the model. C.G.C. provided core advice and checked through the whole paper. All authors have read and agreed to the published version of the manuscript.

Funding: This research was supported by the research fund of Hanyang University (HY-2018) and National Research Foundation of Korea grant, which is funded by the Government of South Korea (NRF-2020R1A2C1008509 and NRF-2019R1A6A3A01097236).

Informed Consent Statement: Not applicable.

Data Availability Statement: The data presented in this study are available on request from the corresponding author. The data are not publicly available because it contains non-public data.

Conflicts of Interest: The authors declare no conflict of interest.

\section{References}

1. Jacobs, J. The Death and Life of Great American Cities; Random House: New York, NY, USA, 1961.

2. Gehl, J. Life between Buildings: Using Public Space; Island Press: Washington, DC, USA, 2011.

3. Cervero, R.; Duncan, M. Walking, bicycling, and urban landscapes: Evidence from the San Francisco Bay area. Am. J. Public Health 2003, 93, 1478-1483. [CrossRef] [PubMed]

4. Cervero, R.; Radisch, C. Travel choices in pedestrian versus automobile oriented neighborhoods. Transp. Policy 1996, 3, $127-141$. [CrossRef] 
5. Coogan, M.A.; Karash, K.H.; Adler, T.; Sallis, J. The role of personal values, urban form, and auto availability in the analysis of walking for transportation. Am. J. Health Promot. 2007, 21, 363-370. [CrossRef] [PubMed]

6. Frank, L.D.; Pivo, G. Impacts of Mixed Use and Density on Utilization of Three modEs of Travel: Single-Occupant Vehicle, Transit, and Walking. Transp. Res. Rec. 1994, 1466, 44-52. Available online: https://www.researchgate.net/publication/235358160_ Impacts_of_Mixed_Used_and_Density_on_Utilization_of_Three_Modes_of_Travel_Single-Occupant_Vehicle_Transit_Walking (accessed on 14 January 2021).

7. Zhang, M. The role of land use in travel mode choice: Evidence from Boston and Hong Kong. J. Am. Plan. Assoc. 2004, 70, 344-360. [CrossRef]

8. Lee, C.; Moudon, A.V. The 3Ds + R: Quantifying land use and urban form correlates of walking. Transp. Res. Part D Transp. Environ. 2006, 11, 204-215. [CrossRef]

9. Frank, L.D.; Engelke, P. Multiple Impacts of the Built Environment on Public Health: Walkable Places and the Exposure to Air Pollution. Inter. Regi. Scie. Rev. 2005, 28, 193-216. [CrossRef]

10. Inoue, S.; Ohya, Y.; Odagiri, Y.; Takamiya, T.; Ishii, K.; Kitabayashi, M.; Suijo, K.; Sallis, J.F.; Shimomitsu, T. Association between perceived neighborhood environment and walking among adults in 4 cities in Japan. J. Epidemiol. 2010, 20, 277-286. [CrossRef]

11. Ewing, R.; Haliyur, P.; Page, G.W. Getting around a traditional city, a suburban planned unit development, and everything in between. Transp. Res. Rec. 1994, 1466, 53-62. Available online: http://onlinepubs.trb.org/Onlinepubs/trr/1994/1466/1466-008 .pdf (accessed on 14 January 2021).

12. Handy, S.L.; Clifton, K.J. Local shopping as a strategy for reducing automobile travel. Transportation 2001, 28, 317-346. [CrossRef]

13. Jeong, H.R.; Choi, C.G. Influence of residents and neighborhood land use on choice of large-scale discount stores: Focused on Seoul in Korea. J. Korea Plan. Assoc. 2013, 48, 219-235.

14. Manoj, M.; Verma, A. Effect of built environment measures on trip distance and mode choice decision of non-workers from a city of a developing country, India. Transp. Res. Part D Transp. Environ. 2016, 46, 351-364. [CrossRef]

15. Im, H.N.; Choi, C.G. The hidden side of the entropy-based land-use mix index: Clarifying the relationship between pedestrian volume and land-use mix. Urban Stud. 2019, 56, 1865-1881. [CrossRef]

16. Lee, Y.S.; Choo, S.H.; Kang, J.M. Analysing key factors to affect change of pedestrian volumes by neighborhood in its in Seoul J. Korea Plan. Assoc. 2013, 48, 197-207. Available online: http:/ /www.dbpia.co.kr/journal/articleDetail?nodeId=NODE0228225 6\&language=ko_KR (accessed on 14 January 2021).

17. Sung, H.G.; Go, D.H.; Choi, C.G. Evidence of Jacobs's street life in the great Seoul city: Identifying the association of physical environment with walking activity on streets. Cities 2013, 35, 164-173. [CrossRef]

18. Cervero, R.; Kockelman, K.M. Travel demand and the 3Ds: Density, diversity, and design. Transp. Res. Part. D Transp. Environ. 1997, 2, 199-219. [CrossRef]

19. Sung, H.; Lee, S.; Cheon, S. Operationalizing Jane Jacobs's urban design theory: Empirical verification from the Great City of Seoul, Korea. J. Plan. Educ. Res. 2015, 35, 117-130. [CrossRef]

20. Cerin, E.; Leslie, E.; Du Toit, L.; Owen, N.; Frank, L.D. Destinations that matter: Associations with walking for transport. Health Place 2007, 13, 713-724. [CrossRef]

21. Lee, J.-A.; Lee, H.; Koo, J.-H. Analysis of factors influencing pedestrian volume based on the physical environment of the street: Focused on major commercial streets in Seoul. J. Korea Plan. Assoc. 2014, 49, 145-163. [CrossRef]

22. Lee, N.H.; Choi, C.G. A study on the influencing factors of time and distance for weekday leisure travel. J. Korea Real Estate Anal. Assoc. 2019, 25, 23-36. Available online: https://www.dbpia.co.kr/journal/articleDetail?nodeId=NODE09252507 (accessed on 14 January 2021).

23. Lee, N.H.; Choi, C.G. A study on the influence factors of weekday leisure travel. J. Korea Plan. Assoc. 2020, 55, 91-99. [CrossRef]

24. Yun, N.Y.; Choi, C.G. An empirical analysis of the relationship between pedestrian volume and pedestrian environmental factors in commercial streets in Seoul. J. Korea Plan. Assoc. 2013, 48, 135-149. Available online: http://www.dbpia.co.kr/journal/ articleDetail?nodeId=NODE02241121\&language $=$ ko_KR (accessed on 14 January 2021).

25. Lee, J.A.; Koo, J.H. The effect of physical environment of the street on pedestrian volume: Focused on the central business district (CBD, GBD, YBD) of Seoul. J. Korea Plan. Assoc. 2013, 48, 269-285. Available online: https://www.dbpia.co.kr/journal/ articleDetail?nodeId=NODE02241129\&language=ko_KR (accessed on 14 January 2021).

26. Lee, K.H.; Ahn, K.H. The correlation between Neighborhood characteristics and walking of residents: A case study of 40 areas in Seoul. J. Korea Plan. Assoc. 2017, 42, 105-118. Available online: http://www.dbpia.co.kr/journal/articleDetail?nodeId=NODE009 26582\&language $=$ ko_KR (accessed on 14 January 2021).

27. Rajamani, J.; Bhat, C.R.; Handy, S.; Knaap, G.; Song, Y. Assessing impact of urban form measures on nonwork trip mode choice after controlling for demographic and level-of-service effects. Transp. Res. Rec. 2003, 1831, 158-165. [CrossRef]

28. Handy, S.L. Regional Versus Local Accessibility: Implications for Nonwork Travel; Working Paper; University of California Transportation Center: Berkeley, CA, USA, 1993.

29. Cho, H.; Lee, S. Analysis of neighborhood environmental characteristics affecting walking activity time: Focused on the difference between subjectively measured- and objectively measured-neighborhood environment. J. Korea Plan. Assoc. 2016, 51, 105-121. [CrossRef]

30. Duncan, M.J.; Winkler, E.; Sugiyama, T.; Cerin, E.; Du Toit, L.; Leslie, E.; Owen, N. Relationships of land use mix with walking for transport: Do land uses and geographical scale matter? J. Urban. Health 2010, 87, 782-795. [CrossRef] 
31. Sung, H.; Lee, S.; Jung, S. Identifying the relationship between the objectively measured built environment and walking activity in the high-density and transit-oriented city, Seoul, Korea. Environ. Plan. B Plan. Des. 2014, 41, 637-660. [CrossRef]

32. Korean Statistical Information Service. Available online: https://kosis.kr/eng/ (accessed on 14 December 2020).

33. Household Travel Diary Survey. 2011. Available online: https://www.ktdb.go.kr/www/contents.do?key=16 (accessed on 14 December 2020).

34. Bhat, C.R.; Gossen, R. A mixed multinomial logit model analysis of weekend recreational episode type choice. Transp. Res. Part B Methodol. 2004, 38, 767-787. [CrossRef]

35. Ohnmacht, T.; Götz, K.; Schad, H. Leisure mobility styles in Swiss conurbations: Construction and empirical analysis. Transportation 2009, 36, 243-265. [CrossRef]

36. Saelens, B.E.; Handy, S.L. Built environment correlates of walking: A review. Med. Sci. Sports Exerc. 2008, 40, S550-S566. [CrossRef] [PubMed]

37. Seoul Metropolitan Government Taxation Ledger; Seoul Metropolitan Government: Seoul, Korea, 2015; (Not Publicly Available).

38. White, J.L. Logistic regression model effectiveness: Proportional chance criteria and proportional reduction in error. Med. Sci. Sports J. Contem. Res. Educ. 2013, 2, 4-10. Available online: https://egrove.olemiss.edu/jcre/vol2/iss1/3 (accessed on 14 January 2021). 